\title{
SISTEM MONITORING DAN PEMBERIAN PAKAN OTOMATIS PADA BUDIDAYA IKAN MENGGUNAKAN WEMOS DENGAN KONSEP INTERNET OF THINGS (IoT)
}

\author{
Rifky Ridho Prabowo ${ }^{1}$, Kusnadi $^{2}$, Ridho Taufiq Subagio ${ }^{3}$ \\ Universitas Catur Insan Cendekia \\ Jl. Kesambi 202, Kota Cirebon, Jawa Barat \\ e-mail : rifkyprabowo2@gmail.com ${ }^{1}$, kusnadi@ cic.ac.id ${ }^{2}$, ridho.taufiq@ cic.ac.id ${ }^{3}$
}

\begin{abstract}
ABSTRAK
Budidaya ikan lele merupakan suatu usaha yang menjanjikan untuk digeluti waktu sekarang, kebutuhan akan ikan yang tinggi dipasaran, membuat terbuka kesempatan untuk berwirausaha di sektor peternakan ikan. Ikan lele yang mudah dikembangkan merupakan salah satu faktor pendukung untuk kemajuan budidaya ikan lele, namun pemberian makan yang tidak tepat waktu bisa jadi penghambat untuk pertumbuhan lele. Tujuan dalam penelitian ini yaitu ingin membuat sebuah alat yang dapat memberikan pakan secara otomatis dan memonitoring ketersediaan pakan dari mana saja menggunakan smartphone. Alat yang digunakan pada penelitian ini yaitu dengan menggunakan board Wemos DI Mini sebagai pengendali dari sistem ini, yang ditambah dengan modul RTC yang dapat membaca waktu untuk penjadwalan pakan, sensor ultrasonik HC-SRO4 yang dapat mendeteksi jarak untuk memonitoring ketersediaan pakan, motor servo yang dapat bergerak untuk membuka dan menutup tempat pakan, buzzer yang berbunyi ketika sensor ultrasonik HC-SRO4 mendeteksi bahwa pakan akan habis, dan juga Telegram sebagai platform yang mendukung IoT pada board Wemos D1 Mini. Hasil penelitian ini yaitu berupa alat untuk memonitoring dan memberikan pakan otomatis. Wemos DI Mini akan mengirimkan pesan notifikasi jika ikan sudah diberimakan dan juga akan mengirimkan pesan peringatan jika pakan dalam tempat pakan akan habis. Selain itu ketersediaan pakan juga dapat di cek melalui telegram, ketika melakukan pengecekan pakan dengan mengirim pesan dari telegram maka akan mengirimkan pesan ketersedian pakan untuk beberapa hari.
\end{abstract}

Kata Kunci : Monitoring, Telegram, Wemos D1 Mini, Modul RTC, Sensor Ultrasonik HC-SR04.

Catfish farming is a promising business for the current time, the need for fish is high in the market, making opportunities for entrepreneurship in the fish farming sector open. Catfish that are easily developed are one of the supporting factors for the progress of catfish farming, but improper feeding can be an obstacle to catfish growth. The purpose of this research is to make a tool that can provide feed automatically and monitor the availability of feed from anywhere using a smartphone. The tool used in this study is by using the Wemos DI Mini board as a controller of this system, which is added with the RTC module that can read time for feed scheduling, HC-SR04 ultrasonic sensor that can detect distances to monitor feed availability, servo motors that can moves to open and close the feed, the buzzer that sounds when the HCSR04 ultrasonic sensor detects that the feed will run out, and also Telegram as a platform that supports IoT on the Wemos DI Mini board. The results of this study are in the form of tools to monitor and provide automatic feed. Wemos DI Mini will send a notification message if the fish have been delivered and will also send a warning message if the feed in the feedlot will run out. Besides the availability of feed can also be checked via telegram, when checking the feed by sending messages from the telegram it will send a message of availability of feed for several days.

Keywords: Monitoring, Telegram, Wemos D1 Mini, RTC Module, Ultrasonic Sensor HC-SR04. 


\section{PENDAHULUAN}

Kegiatan budidaya ikan dalam kolam selalu berkembang dan memiliki prospek yang cerah seiring peningkatan hasil budidaya ikan dari tahun ke tahun. Kementerian Kelautan dan Perikanan (KKP) mencatat produksi perikanan budidaya 2018 sampai dengan September meningkat 29\% dibandingkan tahun lalu. Adapun, saat ini jumlahnya mencapai 5,6 juta ton. Menteri Kelautan dan Perikanan Susi Pudjiastuti mengatakan peningkatan tersebut dikarenakan kerja keras pihaknya memberantas illegal fishing yang merugikan para nelayan. "Produksi ikan hasil budidaya meningkat Januari-September 2018 pertumbuhan 29\% dibandingkan Januari-September 2017," kata dia dalam konferensi pers di KKP, Jakarta, Senin (16/12/2018). Lebih lanjut, kata Susi terdapat lima ikan yang paling menonjol peningkatan produksinya dari kuartal I hingga III 2018, yakni gurame, lele, patin, udang dan nila. Adapun pertumbuhan tersebut masing-masing gurame $68,15 \%$, lele $56,32 \%$, patin $31,76 \%$, udang 30,02\%, dan nila 7,62 \%. (detikFinance, 2018; Produksi Perikanan Budidaya 5,6 Juta Ton, Naik 29\%). Salah satunya adalah kolam budidaya ikan lele yang dikelola secara pribadi yaitu UD. Fish Moldy yang merupakan peternakan ikan milik perorangan yang berlokasi di Kecamatan Rajagaluh Kabupaten Majalengka. Sistem pengelolaan peternakan yang baik adalah faktor utama agar memperoleh ikan yang berkualitas. Salah satunya adalah pemberian pakan yang harus dimonitor agar pemberiannya sesuai dengan frekuensi pakan yang dibutuhkan oleh ikan, kelebihan frekuensi pemberian pakan akan menyebabkan ikan lele sakit, bahkan mati. Sampai sekarang para peternak ikan yang berada di Kecamatan Rajagaluh Kabupaten Majalengka, masih ada yang menggunakan cara manual untuk memberi makan ikan yang dilakukan dengan cara menebar pakan ke kolam pada jam makan ikan, ketika pemilik kolam sedang sibuk atau memiliki urusan lain maka pemberian pakan menjadi tidak tepat pada waktunya. Hal ini bisa menjadi salah satu faktor lambatnya pertumbuhan pada ikan.

Berdasarkan masalah tersebut dibutuhkan sebuah perangkat elektronik sistem monitoring dan pemberian pakan otomatis untuk budidaya ikan yang disampaikan kepada peternak yang memberikan informasi tentang pemberian pakan. Sistem monitoring pemberian pakan harus dapat diakses dengan cepat, mudah, dimana saja dan kapan saja. Sistem kontrol pemberian pakan akan otomatis memberi makan pada jam yang sudah ditentukan. Perangakat sistem monitoring dan pemberian pakan otomatis yang dibuat terdiri dari modul Wemos D1 mini, sensor HC-SR04, Modul RTC, pemanfaatan smartphone android dan fasilitas aplikasi telegram (bot telegram). Perkembangan IoT (Internet of Things) yang seperti sekarang ini dapat juga di manfaatkan sebagai sarana untuk mempermudah peternak dalam memonitoring dan pemberian pakan pada kolam secara otomatis tanpa harus pergi ke kolam secara langsung.

\subsection{Identifikasi Masalah}

Berdasarkan latar belakang masalah diatas, maka penulis menguraikan identifikasi permasalahan sebagai berikut:

1. Pembudidaya masih harus selalu datang ke kolam secara rutin untuk memberi makan ikan.

2. Belum adanya aplikasi untuk memonitoring pemberian pakan ikan secara otomatis.

3. Bagaimana merancang dan membangun hardware dan software yang terintegrasi mampu memberikan pakan otomatis pada kolam ikan.

4. Bagaimana menerapkan sistem otomatisasi dan cara pemberian notifikasi jika ikan sudah diberi makan?

\subsection{Batasan Masalah}

Penulis membatasi permasalahan dalam penulisan ini agar pembahasan tidak menyimpang dari tujuan, maka dilakukan pembatasan masalah sebagai berikut:

1. Mikrokontroler yang digunakan adalah Wemos D1 mini sebagai pengontrol rangkaian.

2. Pengolahan data input perangkat lunak menggunakan software Arduino IDE.

3. Informasi yang dikirim keaplikasi telegram berupa notifikasi.

4. Sistem yang dibuat diperuntukkan untuk jenis ikan lele dalam satu kolam yang berumur sama yaitu 3045 hari.

5. Sistem ini digunakan untuk kolam ukuran $2 \mathrm{~m} \times 1 \mathrm{~m}$ dan kedalaman kolam 0,5-0,7 $\mathrm{m}$.

6. Takaran pakan yang dibuat untuk 10 ikan. 


\subsection{Tujuan}

Adapun tujuan dibuatnya sistem monitoring dan pemberian pakan otomatis ini adalah antara lain sebagai berikut :

1. Membantu dan memudahkan pembudidaya dalam hal pemberian pakan.

2. Memudahkan pembudidaya memonitor pemberian pakan.

3. Mampu menerapkan otomatis pemberian pakan ikan berdasarkan jam yang sudah ditentukan.

4. Membuat sistem untuk mengirim notifikasi ketika sudah dilakukannya pemberian pakan.

\section{LANDASAN TEORI}

\subsection{Budidaya Ikan}

Budidaya perikanan itu sendiri didefinisikan sebagai suatu kegiatan untuk memproduksi biota (organisme) akuatik secara terkontrol dalam rangka mendapatkan keuntungan (profit). Dengan penekanan pada kondisi terkontrol dan orientasi untuk mendapatkan keuntungan tersebut, definisi ini mengandung makna bahwa kegiatan budidaya perikanan adalah kegiatan ekonomi (prinsip-prinsip ekonomi) yang mengarah pada industri (tepat waktu, tepat jumlah, tepat mutu, dan tepat harga). Kegiatan budidaya perikanan diawali oleh kegiatan perikanan tangkap, suatu kegiatan yang sudah dilakukan oleh manusia primitif sejak zaman purba. Produksi perikanan tangkap dibatasi oleh produktivitas alamiah suatu perairan (laut, sungai, danau atau waduk). Produktivitas (produksi bobot biomassa biota air per satuan volume air per waktu) alamiah perairan tersebut dapat ditingkatkan puluhan hingga ribuan kali oleh budidaya perikanan [1].

\subsection{Ikan Lele}

Ikan lele lokal (Clarias batrachus) adalah ikan asli atau endemik di Perairan Sunda (Ng dan Kottelat, 1988). Selain Indonesia, tersebar pula di Afrika Utara, Asia Tenggara, India, Sri Lanka, Bangladesh, Burma, Singapura, dan Borneo. Umumnya ditemukan di perairan tawar dan payau. Di perairan keruh dan minim oksigen terlarut pun, ikan ini mampu hidup. Nama lain ikan ini adalah walking catfish, atau magur, clarias catfish. Pada sirip pektoral terdapat jari-jari sirip keras atau duri tajam (patil) yang runcing, dapat digunakan untuk berjalan di daratan sehingga disebut walking catfish. Ikan ini mempunyai sifat sama dengan ikan lele pada umumnya yaitu nokturnal, pemakan segala (omnivora) dan cenderung predator. Telah mampu mencapai kematangan seksual pada usia 12 bulan baik ikan jantan maupun betina. Ikan lele lokal tidak pernah dilaporkan ada yang mencapai ukuran raksasa Aquatic Invasive Species (2005) mempublikasikan bahwa tidak ditemukan ikan ukuran maksimal yang pernah ditemui di alam hanya mencapai $24 \mathrm{inch}$, sangat berbeda dengan ikan lele dumbo yang dapat mencapai bobot $60 \mathrm{~kg}$ dengan panjang lebih dari $100 \mathrm{~cm}[1]$.

\subsection{Pengertian Sistem}

Sistem adalah suatu kesatuan prosedur atau kumpulan dari komponen-komponen yang memiliki keterkaitan antara satu dan lainnya bekerja bersama-sama sesuai dengan aturan yang diterapkan sehingga terbentuk suatu tujuan yang sama. Dalam sebuah system apabila terjadi salah satu komponen yang tidak bekerja atau rusak maka sistem tidak akan bekerja sesuai dengan yang diinginkan [2]. Berdasarkan kutipan diatas dapat disimpulkan bahwa sistem adalah kumpulan dari beberapa element yang terkait satu sama lain untuk mencapai suatu tujuan yang sama.

\subsection{Internet of Things (IoT)}

Internet of Things merupakan sebuah konsep yang bertujuan untuk memperluas manfaat dari konektivitas internet yang tersambung secara terus-menerus. Adapun kemampuan seperti berbagi data, remote control, dan sebagainya, termasuk juga pada benda di dunia nyata. Contohnya bahan pangan, elektronik, koleksi, peralatan apa saja, termasuk benda hidup yang semuanya tersambung ke jaringan lokal dan global melalui sensor yang tertanam dan selalu aktif. Pada dasarnya, IoT mengacu pada benda yang dapat diidentifikasikan secara unik sebagai representasi virtual dalam struktur berbasis Internet. Istilah Internet Of Things awalnya disarankan oleh Kevin Asthon pada 1999 dan mulai populer melalui Auto-ID Center di MIT [3].

\subsection{Kontrol}

Sistem kontrol adalah proses pengaturan ataupun pengendalian terhadap satu atau beberapa besaran (variabel, parameter) sehingga berada pada suatu harga atau dalam suatu rangkuman harga (range) tertentu. Ada 3 parameter yang harus diperhatikan sebagai sistem kontrol proses yaitu :

1. Cara kerja sistem kontrol.

2. Keterbatasan pengetahuan operator dalam pengontrolan proses. 
3. Peran instrumentasi dalam membantu operator pada pengontrolan proses.

Empat langkah yang harus dikerjakan operator yaitu mengukur, membandingkan, menghitung, mengkoreksi. Pada waktu operator mengamati ketinggian level, yang dikerjakan sebenarnya adalah mengukur process variable (besaran parameter proses yang dikendalikan) [4].

\subsection{Otomatis}

Otomatis Mempunyai arti dengan bekerja sendiri atau dengan sendirinya. Pengertian Pengaturan otomatis atau sistem pengaturan otomatis berasal dari tiga suku kata yaitu Sistem, pengaturan dan otomatis. Sistem adalah sebuah susunan komponen-komponen fisik yang saling terhubung dan membentuk satu kesatuan untuk melakukan aksi tertentu.Pengaturan adalah suatu aktivitas mengatur, mengendalikan, mengarahkan, memerintah.Sedangkan Otomatis adalah dengan bekerja sendiri atau dengan sendirinya. Dalam hal ini istilah pengaturan atau kontrol mengandung tiga aspek atau unsur utama yaitu rencana yang jelas, dapat melakukan pengukuran, dan dapat melakukan tindakan. pengaturan otomatis yang dimaksud adalah "Membuat sesuatu sesuai dengan harapan ataupun rencanan kita dan juga berjalan dengan sendirinya tanpa campur tangan manusia secara langsung" maka kita dapat menganggap suatu sistem kontrol otomatis adalah suatu sistem yang dapat membuat agar keluaran (output) sistem sesuai dengan rencana dan keinginan yang diharapkan [5].

\subsection{Mikrokontroller}

Mikrokontroler atau kadang dinamakan pengontrol tertanam (embedded controller) adalah suatu sistem yang mengandung masukkan atau keluaran, memori, dan prosesor yang digunakan pada produk seperti mesin cuci, pemutar video, mobil dan telepon. Pada prinsipnya, Mikrokontroler adalah sebuah komputer berukuran kecil yang dapat digunakan untuk mengambil keputusan, melakukan hal-hal bersifat berulang dan dapat berinteraksi dengan peranti-peranti eksternal, seperti sensor ultrasonik untuk mengukur jarak terhadap suatu objek, penerima GPS untuk memperoleh data posisi kebumian dari satelit dan motor untuk mengontrol gerak pada robot. Sebagai komputer yang berukuran kecil, Mikrokontroler cocok diaplikasikan pada benda-benda yang berukuran kecil, misalnya sebagai pengendali pada robot .

\subsection{Motor Servo}

Motor servo adalah sebuah motor dengan sistem umpan balik tertutup di mana posisi dari motor akan diinformasikan kembali ke rangkaian kontrol yang ada di dalam motor servo. Motor ini terdiri dari sebuah motor DC, serangkaian gear, potensiometer dan rangkaian kontrol. Potensiometer berfungsi untuk menentukan batas sudut dari putaran servo. Sedangkan sudut dari sumbu motor servo diatur berdasarkan lebar pulsa yang dikirim melalui kaki sinyal dari kabel motor.

\subsection{Buzzer}

Buzzer adalah sebuah komponen yang memiliki fungsi mengubah arus listrik menjadi suara. Dan pada dasarnya prinsip kerja buzzer hampir sama dengan speaker. Buzzer terdiri dari sebuah diafragma yang memiliki kumparan. Ketika kumparan tersebut dialiri arus listrik sehingga menjadi elektromagnet, kumparan akan tertarik ke dalam atau keluar tergantung dari polaritas magnetnya. Karena kumparan dipasang pada diafragma maka setiap getaran diafragma secara bolak-balik sehingga membuat udara bergetar dan menghasilkan suara [6].

\subsection{Modul RTC DS3231}

RTC (Real Time Clock) merupakan chip IC yang mempunyai fungsi menghitung waktu yang dimulai dari detik, menit, jam, hari, tanggal, bulan, hingga tahun dengan akurat. Untuk menjaga atau menyimpan data waktu yang telah di-ON-kan pada modul terdapat sumber catu daya sendiri yaitu baterai jam kancing, serta keakuratan data waktu yang ditampilkan digunakan osilator kristal eksternal. Contoh yang dapat ditemui dalam kehidupan sehari - hari yaitu pada motherboard PC yang biasanya letaknya berdekatkan dengan chip BIOS. Difungsikan guna menyimpan sumber informasi waktu terkini sehingga jam akan tetap up to date walaupun komputer tersebut dimatikan [7].

Sistem Monitoring Dan Pemberian Pakan Otomatis Pada Budidaya Ikan Menggunakan Wemos Dengan Konsep Internet Of Things (IoT) -( Rifky Ridho Prabowo, Kusnadi, Ridho Taufiq Subagio) 


\subsection{Sensor Ultrasonik HC-SR04}

Sensor Ultrasonik HC-SR04 adalah sensor pengukur jarak berbasis gelombang ultrasonik. Prinsip kerja sensor ini mirip dengan radar ultrasonik. Gelombang ultrasonik di pancarkan kemudian di terima balik oleh receiver ultrasonik. Jarak antara waktu pancar dan waktu terima adalah representasi dari jarak objek. Sensor ini cocok untuk aplikasi elektronik yang memerlukan deteksi jarak. Sensor Ultrasonik HC-SR04 adalah versi low cost dari sensor ultrasonic PING buatan parallax. Perbedaaannya terletak pada pin yang digunakan. HC-SR04 menggunakan 4 pin sedangkan PING buatan parallax menggunakan 3 pin. Pada Sensor Ultrasonik HC-SR04 pin trigger dan output diletakkan terpisah. Sedangkan jika menggunakan PING dari Parallax pin trigger dan output telah diset default menjadi satu jalur. Tidak ada perbedaaan signifikan dalam pengimplementasiannya. Jangkauan karak sensor lebih jauh dari PING buatan parllax, dimana jika ping buatan parllax hanya mempunyai jarak jangkauan maksimal $350 \mathrm{~cm}$ sedangkan sensor ultrasonik HC-SR04 mempunyai kisaran jangkauan maksimal 400-500cm.

\subsection{Arduino IDE}

Arduino IDE dibuat dari bahasa pemrograman JAVA. Arduino IDE juga dilengkapi dengan library $\mathrm{C} / \mathrm{C}++$ yang bisa disebut wiring yang membuat operasi input dan output menjadi lebih mudah. Arduino $I D E$ im dikembangkan dari software processing yang dirombak menjadi Arduino IDE khusus untuk pemrograman dengan arduino. Program yang ditulis dengan menggunakan arduino software (IDE) disebut sebagai sketch. Sketch ditulis dalam suatu editor teks dan disrmpan dalam file dengan ekstensi ino. Teks editor pada arduino software memiliki fitur-fitur seperti cutting, paste dan searching replacing sehingga memudahkan kamu dalam menuliskan kode program. Pada software ardumo IDE, terdapat semacam message box berwarna hitam yang berfungsi menampilkan status, seperti pesan error, compile, dan upload program. Di bagian bawah paling kanan software arduino $I D E$, menunjukan board yang terkonfigurasi beserta COM ports yang digunakan.

\subsection{Fritzing}

Fritzing adalah suatu software atau perangkat lunak gratis yang digunakan oleh desainer, seniman, dan para penghobi elektronika untung perancangan berbagai peralatan elektronika. antarmuka fritzing dibuat seinteraktif dan semudah mungkin agar bisa digunakan oleh orang yang minim pengetahuannya tentang simbol dari perangkat elektronika. Di dalam fritzing sudah terdapat skema siap pakai dari berbagai mikrokontroller arduino serta shieldnya. Software ini memang khusus dirancang untuk perancangan dan pendokumentasian tentang produk kreatif yang menggunakan mikrokontroller arduino[8].

\subsection{Telegram}

Telegram merupakan aplikasi perpesanan yang memfokuskan diri pada performa dan tingkat keamanan yang lebih dengan tampilan sederhana serta gratis dalam menggunakannya. Aplikasi telegram dapat digunakan pada perangkat ponsel smartphone, tablet, atau perangkat komputer. Telegram juga menyediakan layanan kirim pesan berupa foto, video dan jenis berkas lainnya (.doc, .zip, .mp3, dan lainlain), serta dapat membuat grup chatting dengan kapasitas 10.000 pengguna di dalamnya. Aplikasi telegram sendiri pertama kali dirilis pada 14 Agustus 2013 oleh Nikolai Durov dan Pavel. Tidak terbatas hanya diperuntukan bagi pengguna biasa saja, melainkan Telegram memberikan akses secara terbuka untuk para pengembang aplikasi terutama di bidang IoT yang memanfaatkan Telegram dengan dibuatnya layanan Bots.

Pada Juni 2015, telegram meluncurkan platform pengembangan pihak ketiga untuk menciptakan sebuah platform yang dinamakan Telegram Bot. Sebagai aplikasi yang menyediakan layanan terbuka seperti akses API (Application Programming Interface) yang dimilikinya, Telegram meluncurkan API Bot sebagai aplikasi pihak ketiga dengan tujuan pemanfaatan bagi para pengembang aplikasi. Telegram Bot sendiri merupakan sebuah akun Telegram yang dikendalikan oleh perangkat lunak yang memiliki fitur AI (Artificial Intelligence) dengan kemampuan seperti memberikan panduan, bermain, mencari suatu data, menyebarkan pesan atau berita, sebagai pengingat, juga sebagai penghubung suatu perangkat yang dapat dikendalikan melalui Telegram Bot tersebut. Dengan adanya fitur Telegram Bot yang dimiliki oleh aplikasi Telegram, banyak para pengembang perangkat lunak mengintegrasikan aplikasi yang mereka buat dengan perangkat lainnya dengan pemanfaatan Telegram Bot menggunakan jaringan internet. 


\section{PERANCANGAN SISTEM}

\subsection{Flowchart Pemberian Pakan Otomatis}

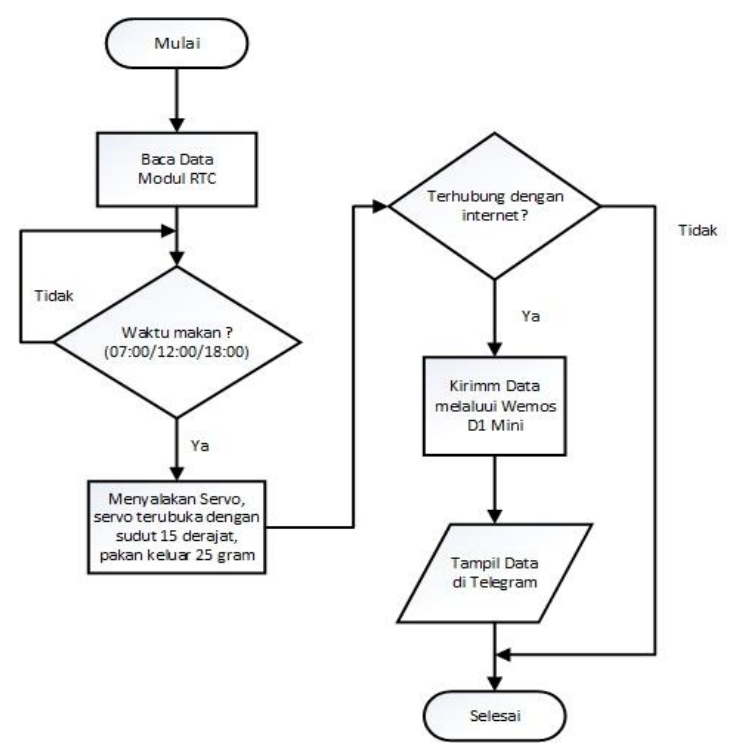

Keterangan :

\section{Gambar 1. Flowchart Pemberian Pakan Otomatis}

Proses pemberian pakan ikan secara otomatis sesuai dengan penjadwalan yang sudah diatur dengan modul RTC. Ketika Wemos D1 mini dinyalakan maka modul RTC akan aktif. Jika waktu sudah sesuai dengan jam yang sudah ditentukan maka motor servo akan bergerak untuk membuka tempat pakan 15o selama satu detik dan setelah itu akan menutup kembali. Jika Wemos D1 mini terhubung dengan internet maka Wemos D1 mini akan mengirimkan notifikasi ke Telegram bahwa ikan sudah diberi makan.

\subsection{Flowchart Monitoring Ketersediaan Pakan}
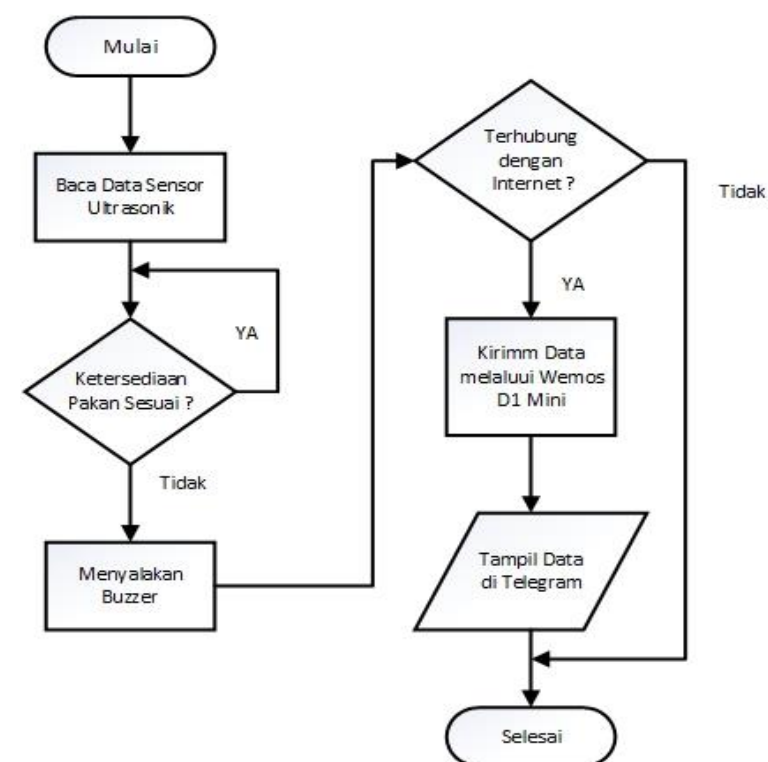

Gambar 2. Flowchart Monitoring Ketersediaan Pakan

Sistem Monitoring Dan Pemberian Pakan Otomatis Pada Budidaya Ikan Menggunakan Wemos Dengan Konsep Internet Of Things (IoT) -( Rifky Ridho Prabowo, Kusnadi, Ridho Taufiq Subagio) 
Keterangan :

Ketika Wemos dinyalakan maka sensor ultrasonik HC-SR04 akan aktif. Setelah itu sensor akan mendeteksi ketersediaan pakan pada tempat pakan. Jika jarak antar sensor dan permukaan pakan sesuai yang diinginkan maka sensor akan terus mendeteksi ketersediaan pakan dan jika jarak antar sensor dan permukaan pakan tidak sesuai yang diinginkan (akan habis) maka buzzer akan menyala dan mengirimkan notifikasi ke Telegram.

Rencana Penjadwalan Pemberian Pakan diberikan berdasarkan waktu dan jam, sebagai berikut:

Tabel 1. Rencana Pemberian Pakan

\begin{tabular}{|c|l|c|}
\hline No & \multicolumn{1}{|c|}{ Waktu } & Jam \\
\hline 1 & Pagi & 7 \\
\hline 2 & Siang & 12 \\
\hline 3 & Sore & 6 \\
\hline
\end{tabular}

Rencana takaran pakan Berdasarkan penelitian 1 kolam berisi $150 \mathrm{~kg}$ ikan, $1 \mathrm{~kg}=30 \mathrm{ikan}$, jadi dalam satu kolam ada $4500 \mathrm{ikan}$, jadi berat $1 \mathrm{ikan}$ adalah $150 \mathrm{~kg} \div 4500=33$ gram. Adapun rencana pengaturan takaran pakan yang diberikan adalah $7 \%$ dari berat badan ikan sesuai dengan pakan dibutuhkan untuk perkembangan ikan usia 30 sampai 45 hari.

pakan $=($ berat ikan $) /(7 \%)$

pakan $=(33$ gram $) /(7 \%)=2.31$ gram

berdasarkan perhitungan 1 ekor ikan membutuhkan 2.31 gram pakan untuk sekali makan, ikan lele butuh 3 kali makan dalam sehari, jadi 1 ekor ikan membutuhkan kurang lebih 7 gram pakan setiap hari.

Rencana ketersediaan pakan Berdasarkan penelitian 1 ekor ikan lele yang berumur 30 hari membutuhkan sekitar 7 gram pakan setiap hari, tempat pakan akan di isi pakan untuk 5 hari, misal jarak sensor ultrasonik HC-SR04 ke pakan yang tersedia adalah $6 \mathrm{~cm}$, dan jarak pakan dan sensor ultrasonik HCSR04 akan berkurang 3cm setiap hari, makan ketika jarak sensor ultrasonik HC-SR04 dan pakan mencapai lebih dari $9 \mathrm{~cm}$, sensor akan mengirimkan notifikasi bahwa ketersediaan pakan akan habis.

\subsection{Diagram Blok Cek Koneksi antara Wemos dan Telegram}

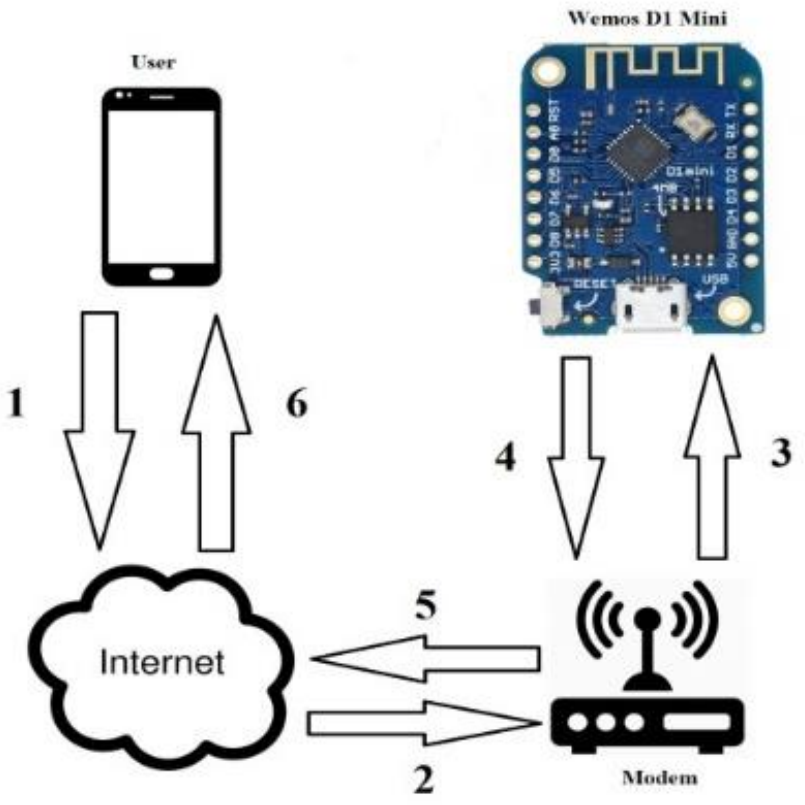

Gambar 3. Diagram Blok Cek Koneksi antara Wemos D1 Mini dan Telegram 
Keterangan :

1. User memberikan action perintah "/mulai" pada Bot Telegram untuk melihat apakah Wemos D1 mini sudah terhubung dan akan menampilkan pilihan "/cekpakan" untuk melihat ketersediaan pakan pada tempat pakan sewaktu-waktu bila diperlukan.

2. Agar perintah dapat terkirim membutuhkan koneksi internet, maka dibutuhkan modem agar dapat berkomunikasi dengan Wemos D1 mini melalui modul WiFi ESP8266 yang sudah tersedia di Wemos D1 mini. Dengan adanya modem ini bisa berguna untuk menyebarkan sinyal WiFi, agar modul Wemos D1 mini dapat terkoneksi dengan internet malalui jaringan WiFi yang sudah tersedia di modul Wemos D1 mini.

3. Setelah Wemos D1 mini terhubung dengan internet, maka perintah "/mulai" Wemos D1 mini yang dikirim dari Bot Telegram dapat diterima.

4. Wemos D1 mini mengirim notifikasi berisi pesan bahwa Wemos D1 mini sudah terhubung, agar notifikasi dapat terkirim membutuhkan koneksi internet dari modem.

5. Agar notifikasi dapat terkirim ke Bot Telegram dibutuhkan koneksi internet agar bisa terhubung dengan Telegram.

6. Bot Telegram menerima notifikasi pesan bahwa Wemos D1 mini sudah terhubung ke internet

\subsection{Diagram Blok Pemberian Pakan Otomatis}
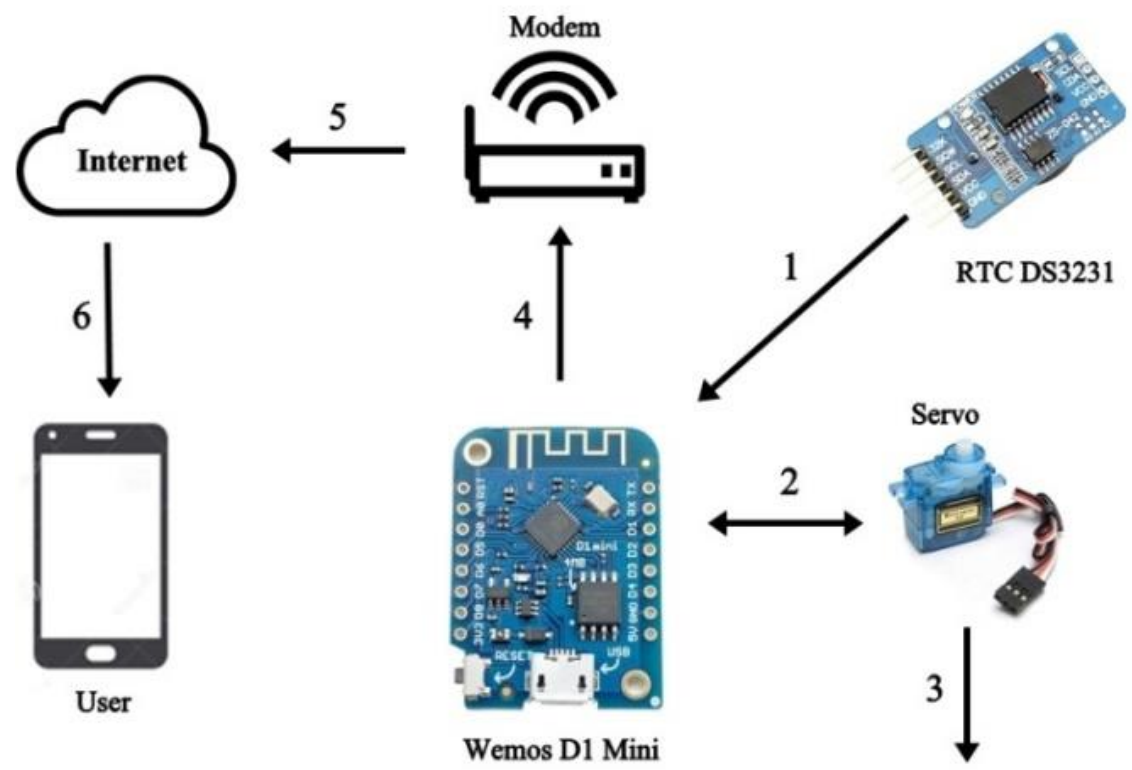

Wemos D1 Mini

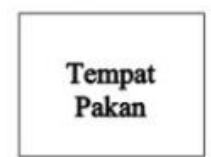

Gambar 4. Diagram Blok Sistem Penjadwalan Pemberian Pakan Otomatis

Keterangan :

1. Modul RTC dalam keadaaan standby akan melakukan aktifitas memonitoring waktu, dan hasil informasi monitoring akan dikirim ke Wemos D1 Mini.

2. Data hasil monitoring dari Modul RTC akan diterima oleh Wemos D1 Mini, dan jika data tersebut sesuai dengan waktu makan yang sudah ditentukan maka Wemos D1 Mini akan mengirimkan perintah untuk menggerakan servo. 
3. Servo akan membuka dan menutup tempat pakan ikan sekian detik setelah mendapat perintah dari Wemos D1 Mini, lalu pakan akan jatuh ke kolam.

4. Setelah ikan sudah diberi makan Wemos D1 Mini akan mengirimkan data berupa notifikasi bahwa ikan sudah diberi makan, data tersebut akan dikirim ke akun TelegramBot pengguna, tapi agar dapat terkirim membutuhkan internet, maka dibutuhkan modem agar dapat saling berkomunikasi dengan Wemos D1 Mini melalui modul Wi-Fi ESP8266 yang sudah tersedia di Wemos D1 Mini.

5. Dengan adanya modem ini bisa berguna untuk menyebarkan sinyal Wi-Fi, supaya modul Wemos D1 Mini dapat terkoneksi melalui jaringan Wi-Fi yang sudah tersedia di modul Wemos D1 Mini berupa Wi-Fi ESP8266.

6. Setelah Wemos D1 terhubung dengan internet, maka data hasil monitoring dapat dikirim ke akun TelegramBot pengguna.

\subsection{Diagram Blok Monitoring Ketersediaan pakan}
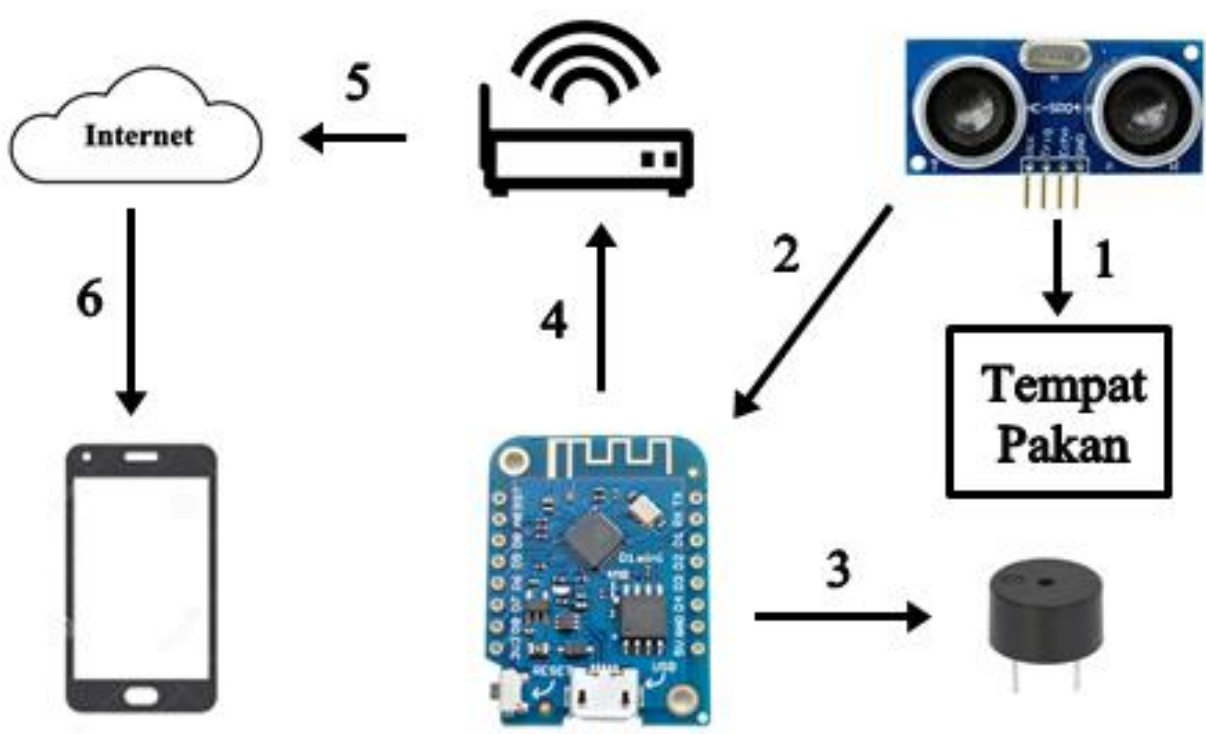

Gambar 5. Diagram Blok Sistem Monitoring Ketersediaan Pakan

Keterangan :

1. Sensor Ultrasonik HC-SR04 dalam keadaan stand by akan melakukan monitoring ketersediaan pakan dengan cara mengukur jarak antara sensor dan permukaan pakan dalam satuan centimeter $(\mathrm{cm})$.

2. Data hasil informasi monitoring sensor ultrasonik akan dikirim ke Wemos D1 Mini.

3. Jika data dari sensor ultrasonik menunjukan bahwa pakan akan habis, maka Wemos D1 Mini akan menyalakan buzzer.

4. Lalu Wemos D1 Mini akan mengirimkan notifikasi ke TelegramBot pengguna bahwa ketersediaan pakan akan habis. Agar dapat terkirim membutuhkan internet, maka dibutuhkan modem agar saling berkomunikasi dengan Wemos D1 mini melalui modul WiFi esp8266 yang sudah tersedia di Wemos D1 mini.

5. Dengan adanya modem ini bisa berguna untuk menyebarkan sinyal WiFi, supaya modul Wemos D1 mini dapat terkoneksi dengan internet malalui jaringan WiFi yang sudah tersedia di modul Wemos D1 mini.

6. Setelah Wemos D1 mini terhubung dengan internet, maka notifikasi bahwa ketersediaan pakan akan habis dapat dikirimkan ke TelegramBot pengguna. 


\section{PENGUJIAN ALAT}

\subsection{Pengujian Motor Servo}

Tabel 2. Pengujian Motor Servo

\begin{tabular}{|c|c|c|c|}
\hline No & Sudut Motor Servo & $\begin{array}{c}\text { Waktu } \\
\text { (detik) }\end{array}$ & $\begin{array}{c}\text { Berat Pakan } \\
\text { (gram) }\end{array}$ \\
\hline 1 & $15^{\circ}$ & 1 & 25 \\
\hline 2 & $20^{\circ}$ & 1 & 33 \\
\hline 3 & $25^{\circ}$ & 1 & 42 \\
\hline
\end{tabular}

Berdasarkan pengujian untuk menentukan sudut motor servo ketika membuka tempat pakan dalam satu detik, didapatkan hasil bahwa sudut yang sesuai adalah $15^{\circ}$. Karaena berat pakan yang dibutuhkan untuk 10 ikan lele berumur 30-45 hari adalah 24 gram, kelebihan berat pakan 1 gram masih dalam batas wajar.

\subsection{Pengujian Motor Servo pada sudut $15^{\circ}$}

Tabel 3. Pengujian Motor Servo pada sudut 15 $^{\circ}$

\begin{tabular}{|c|c|c|c|}
\hline No & Sudut Motor Servo & $\begin{array}{c}\text { Waktu } \\
\text { (detik) }\end{array}$ & $\begin{array}{c}\text { Berat Pakan } \\
\text { (gram) }\end{array}$ \\
\hline 1 & $15^{\circ}$ & 1 & 26 \\
\hline 2 & $15^{\circ}$ & 1 & 24 \\
\hline 3 & $15^{\circ}$ & 1 & 23 \\
\hline 4 & $15^{\circ}$ & 1 & 25 \\
\hline 5 & $15^{\circ}$ & 1 & 25 \\
\hline 6 & $15^{\circ}$ & 1 & 25 \\
\hline \multicolumn{3}{|c|}{ Kesalahan } & $1-2$ \\
\hline
\end{tabular}

Berdasarkan pengujian motor servo pada sudut $15^{\circ}$ dalam satu detik, didapatkan hasil bahwa pada sudut $15^{\circ}$ dalam waktu satu detik mengeluarkan pakan sekitar 24-26 gram, kelebihan 2 gram pada saaat pengeluaran pakan masih dalam batas wajar.

\subsection{Pengujian Penjadwalan Waktu Pemberian Makan Ikan}

Tabel 4. Penjadwalan Waktu Pemberian Makan Ikan

\begin{tabular}{|c|c|c|}
\hline No & $\begin{array}{c}\text { Waktu pemberian } \\
\text { pakan }\end{array}$ & Waktu pakan keluar \\
\hline 1 & $07: 00$ & $06: 00: 06$ \\
\hline 2 & $12: 00$ & $12: 00: 01$ \\
\hline 3 & $18: 00$ & $18: 00: 14$ \\
\hline
\end{tabular}

Berdasarkan pengujian penjadwalan waktu pemberian makan ikan, didapatkan hasil bahwa penjadwalan tersebut berjalan dengan baik, keterlambatan pemberian pakan tidak sampai melebihi 1 menit, keterlambatan pemberian pakan dalam beberapa detik masih dalam batas wajar. 


\section{KESIMPULAN DAN SARAN}

\subsection{Kesimpulan}

Berdasarkan hasil dari Sistem Monitoring dan Pemberian Pakan Otomatis Pada Budidaya Ikan

Menggunakan Wemos Dengan Konsep Internet Of Things (IoT) ini dapat disimpulkan sebagai berikut :

1. Ketepatan waktu dalam pemberian pakan pada ikan karena sudah dijadwalkan dalam sistem dengan Modul RTC dan memberikan kemudahan bagi pembudidaya karena tidak perlu datang ke kolam untuk memberi pakan ikan.

2. Adanya sensor ultrasonik HC-SR04 untuk memonitoring ketersediaan pakan yang nantinya dapat mengirimkan notifikasi ketika pakan habis dan pembudidaya dapat mengecek ketersediaan pakan pada tempat pakan.

3. Dengan adanya buzzer, sistem dapat memberitahu bahwa pakan habis dengan cara buzzer berbunyi. Ini menjadi alternatif ketika internet mati.

4. Dengan menggunakan modul RTC, sensor ultrasonik HC-SR04, motor servo dan buzzer yang terhubung ke Wemos D1 Mini sehingga dapat melakukan otomatisasi pemberian pakan dan memonitoring ketersediaan pakan dengan Aplikasi Telegram yang telah terpasang pada smartphone.

\subsection{Saran}

Berdasarkan percobaan dan pembuatan prototype ini, ada beberapa saran dan masukan agar kedepannya prototype ini dapat lebih baik lagi sehingga dapat direalisasikan, diantaranya :

1. Menggunakan tempat yang lebih besar agar dapat menampung lebih banyak pakan untuk satu minggu atau bulan.

2. Untuk menambah titik, gunakan board yang memiliki spesifikasi diatas Wemos D1 Mini, salah satu contohnya Wemos D1.

3. Menambahkan perintah supaya bisa diatur takaran dan waktu penjadwalan pemberian pakannya berdaasarkan umur ikan.

4. Penambahan kipas atau pelontar pada ujung jatuhnya tempat pakan jika ukuran kolam lebih dari $2 \times 1 \mathrm{~m}$ supaya pakan bisa menyebar ke seluruh permukaan kolam, agar pemberian pakan merata ke semua ikan.

5. Perancangan alat yang lebih baik lagi agar bisa diletakan diluar ruangan, seperti dibuatkan tempat atau ditutup dengan akrilik yang rapi supaya tidak terkena air hujan atau udara yang bisa menyebabkan kerusakan dan korosif pada alat (berkarat).

\section{DAFTAR PUSTAKA}

[1] Effendi. (2004). Budidaya Perikanan. 188.

[2] Fernando Napitupulu Ekki Kurniawan, S.T., M.S.c. Cahyantari Ekaputri, S. T. M. T. (2017). 11231. 4(2), 1449-1456.

[3] Dewantoro, W. (2016). Jurnal Ilmiah Komputer dan Informatika (KOMPUTA ) pembangunan sistem pantau smart fish farm menggunakan arduino berbasis internet of things ( iot ) terhadap budidaya ikan Wisnu Dewantoro Teknik Informatika - Universitas Komputer Indonesia Jurnal Ilmiah K. 2016, 1-8.

[4] Sari, M. (2010). Penggunaan Sensor RTD pada Line Fuel Gas K-4508 Unit Produk Drum (Aplikasi PT. Arun NGL). Skripsi Fakultas Teknik Universitas Sumatera Utara, 15-28.

[5] Albet, M., Ginta, P. W., \& Sudarsono, A. (2014). Pembuatan Jendela Otomatis Menggunakan Sensor Cahaya. Jurnal Media Infotama, 10(1), 8-15.

[6] Efrianto, E., Ridwan, R., \& Fahruzi, I. (2016). Sistem Pengaman Motor Menggunakan Smartcard Politeknik Negeri Batam Electrical Engineering. Integrasi, 8(1), 1-5.

[7] Muhammad Juhan Dwi Suryanto; Tri Rijanto. (2019). Rancang Bangun Alat Pencatat Biaya Pemakaian Energi Listrik pada Kamar Kos Menggunakan Modul Global System For Mobile Communications (GSM) 800L Berbasis Arduino Un. Jurusan Teknik Elektro, 8, 47-55.

[8] Ahmad, F., Nugroho, D. D., \& Irawan, A. (2015). Rancang Bangun Alat Pembelajaran Microcontroller. Jurnal PROSISKO, Vol. 2 No.(1), 10-18. 